\title{
Technology Transfer - The Human Side of IT
}

\author{
Edward Holden \\ Rochester Institute of Technology, Rochester, NY, USA
}

\author{
eph@it.rit.edu
}

\begin{abstract}
Information Technology (IT) is fundamentally a people business that involves integrating technology into human processes in order to solve problems and create new capacities. These integration skills are not often taught in undergraduate computing curricula. The Galisano College of Computing and Information Sciences at Rochester Institute of Technology (RIT) has been offering a course in the diffusion of innovations for several years now and considers the communication needed to diffuse an innovation core to IT's mission.
\end{abstract}

The course, called Technology Transfer, is the study of the "flow" of technology from its creation through adoption to implementation and eventual effects. Our BS in Information Technology has one of the few courses that address these issues directly. Many students are skeptical of the reality of organizational life and fail to understand the way that change actually occurs. The course provides a framework by which students can interpret and understand their roles as change agents in the organization.

This paper provides an overview of RIT's Technology Transfer course, explains its rationale within the curriculum and its contribution to professional practice. It also discusses some of the techniques used in teaching these skills. The paper concludes with feedback on the value of the course to our graduates.

Keywords: Technology Transfer, Diffusion of Innovations, Innovation, Communication

\section{Introduction}

The IT business is fundamentally a people business, yet often, people who are involved in IT underplay the human interaction and emphasize the technical aspects. The technical aspects are key, but without understanding the people and organizations involved, new innovations often are not accepted, even if they are good ideas (Rogers, 1995). Thus, the adoption of an innovation is often inhibited by the lack of understanding of the population being impacted.

Technology transfer, often called the diffusion of innovations, is the process where an innovation is communicated through a social system over time (Rogers, 1995). The IT professional must often play the role of change age nt in the diffusion process. The change agent is responsible for influencing clients to accept the innovation and bring about change in the organization. They must understand the innovation, its impact on the organization, and be able to implement it.

Diffusion theory is an offshoot of communication theory. Although diffusion research existed in many

Material published as part of these proceedings, either on-line or in print, is copyrighted by Informing Science. Permission to make digital or paper copy of part or all of these works for personal or classroom use is granted without fee provided that the copies are not made or distributed for profit or commercial advantage AND that copies 1) bear this notice in full and 2) give the full citation on the first page. It is permissible to abstract these works so long as credit is given. To copy in all other cases or to republish or to post on a server or to redistribute to lists requires specific permission from the publisher at Publisher@InformingScience.org disciplines, it did not take off until the 1960's, and has grown steadily since then. It has its roots in several disciplines including Anthropology, Economics, Psychology, Sociology and Communications (Rogers, 1995). The course is primarily based on the work of Everett Rodgers and his book Diffusion of Innovations (Rogers, 1995). 
IT Students at RIT are required to take core courses in four different areas: Programming and Application Development, Web and Multimedia Development, Hardware and Networking, and User-Centered Deployment before they begin work in their concentration areas. All students are required to take these courses because we believe that IT is about integration therefore a broad knowledge of technology is needed in addition to specific subject area knowledge. Advanced courses in specialty areas often require knowledge from one of the core courses. For example, networking requires some programming; web site design requires some database and interface design, and so on.

Our Technology Transfer Course falls into the User-Centered Deployment core courses along with Human Factors, Interface Design and Development, and Needs Assessment. Students taking Technology Transfer must have third year standing and we prefer that they have completed at least one cooperative education work experience, although this latter desire is not always possible.

\section{Technology Transfer Course Overview}

\section{The Definition of Technology and Innovation}

The course begins with the definition of technology. One of the key ideas that we want to emphasize is that technology can come in many forms. It can be product technology (tangible), process technology (intangible methods) or one type embedded in the other. Undergraduate students seem to have an easy time grasping the tangible technology, but have a harder time with intangible technology.

To help them understand process technology, we discuss examples such as the program deve lopment life cycle, or a systems development methodology. They learn that processes like the Capability Maturity Model (CMM) is a process to manage processes. This helps them understand that process is, in and of itself, technology.

Next we look at the question of embedded technology. For example, the process of capturing an image is imbedded in a camera (product). Similarly, certain products, like a computer with a source control system can be embedded in a program development process.

Once students realize that technology can have many forms we move on to the concept of innovation. An innovation is not necessarily new technology or the result of an invention, but is something that is perceived as new by an organization or social system (Spence, 1994). An innovation is some product or process that is being put into place for use within an organization for the first time, whether it is old or new technology.

\section{Social Systems and Opinion Leaders}

We then emphasize that social systems and subsystems of people are key to the acceptance or rejection of an innovation. Systems and subsystems are governed by norms that impact the users perception of the innovation. In each system there are people who are well respected within the system. These people are called opinion leaders, and although they do not necessarily have any positional authority, others do look to them for technical leadership. The change agent needs to find these people and work with them to make sure that they understand the nature of the innovation (change) that is about to occur and must gain their approval. This will improve the likelihood that the innovation will be accepted.

\section{The Lifecycle of Innovation}

We then acquaint students with the stages that an innovation takes as it progresses through its lifecycle. The stages of Basic Research, Applied R\&D, Commercialization, Diffusion and Consequences are discussed (Rogers, 1995). The emphasis here is for students to understand that there is a continuum of activities that are needed at each stage. Often IT professionals will look at the commercialization stage as being their only involvement, but the other stages are also essential. 
One example used to illustrate this lifecycle is the invention of Organic Light-Emitting Diode (OLED) technology at Eastman Kodak Company This is followed through the lifecycle as it progresses from a glowing mass on a basic researcher's bench to a 15-inch flat panel display screen prototype recently shown with partner Sanyo. The new display has a bright, crisp, clear image that looks like a photograph, only with motion. Up to this point OLED has only been used for small screens such as those on cell phones and cameras (Rand, 2002).

OLED began life when a researcher discovered that an organic compound glowed on his bench. He studied the science behind the organic compound in order to understand the phenomenon. This is called basic research and is aimed at discovering the scientific rules that produce a particular phenomenon in nature. Basic research is not normally concerned with an application, but focused on understanding the science.

After basic research comes applied research and development (R \& D). This stage in the product lifecycle tries to solve a specific problem using the science that has been discovered in the past. Kodak applied OLED to the problem of producing small display screens that were brighter than current screens but consumed less power. They were successful in developing these small screens. While applied research attempts to fit the technology to the problem, the development process tries to figure out how to reliably manufacture the product in sufficient quantities to satisfy consumers. Kodak has done this with very small screens and currently manufactures them with Sanyo.

Commercialization is the process where the innovator learns to make, package, market and distribute the innovation. For products this is generally the result of $\mathrm{R} \& \mathrm{D}$ but for a process it is the result of practice. Kodak has successfully commercialized small screens and now must do this for larger screens such as the 15-inch monitor mentioned above.

The final step in the lifecycle is diffusion - getting people to accept the innovation and spreading it throughout the social system. This becomes the focus of the remainder of the course. While diffusing the innovation we must be concerned with the consequences that the innovation will have on the social system, both positive and negative.

\section{The Seven Key Concepts of Diffusion Theory}

Next, students are taught the seven key concepts of diffusion theory. These key concepts are:

○ Diffusion is the way in which "something spreads" over a population

- Adopters pass through certain stages on the road to acceptance or rejection of an innovation

○ Individuals in a system are connected by communication links that enable information to spread

○ Interpersonal influences produce change

○ Gatekeepers control access to information

○ People adopt innovations at different rates

○ Users' perceptions of the characteristics of the innovation influence the innovation's adoption These key concepts are discussed below.

\section{Diffusion - the way something spreads}

The first key concept is that diffusion is the way in which "something spreads" over a population (social system or organization). Similar to the way news of election results or a major disaster travels through a society, technical innovations are communicated in a number of different ways. This can be through formal presentations, but more likely through observation and personal discussion. Students discuss in- 
formation that describes how the innovation is likely to spread and how to use that information to advance the innovation in the social system.

\section{Stages in the Innovation-Decision Process}

The second key concept is that adopters pass through certain stages on the road to acceptance or rejection of an innovation. These stages in the innovation-decision process are (Rogers, 1995):

○ Knowledge

○ Persuasion

○ Decision

○ Implementation

○ Confirmation

Long lasting negative impacts may be felt if any of these stages are skipped in the rush to get to implementation, yet this is often the case. During the knowledge stage potential users become aware of the innovation. People have a tendency to pay attention to the things in which they are interested. They may see that an innovation fills a need or offers some potential benefit over the current situation. Techniques that work best at this stage are those that reach large numbers of the target audience and include brochures, mass media and advertising. The techniques used should emphasize how the product works, its benefits and features. The goal is to generate awareness and interest on the part of the target audience.

The persuasion stage follows the knowledge stage. In the persuasion stage, it is important to allow the clients to conceive of using the inno vation in their own environment. It is essentially the client "mentally trying on" the innovation. The benefits of this innovation over the current situation or other technology should be emphasized. Techniques that can be used at this stage include a trial of the innovation, site visits to organizations already using the technology, or free samples. Training key people can also be used here if a trial is not possible. Training can help users to visualize how the technology could work in their environment.

The next stage is the decision stage. Here the organization must weigh the factors involved in using the innovation. The change agent may present the advantages of using the technology or continue some of the persuasion activities mentioned in the last paragraph. The key is getting the organization to weigh the benefits of this alternative over others, including their current situation. This can be presented in a number of different ways such as side-by-side comparisons or ratings of alternatives against weighted criteria.

Once the decision has been made to adopt a technology, we enter the implementation stage. During this stage, a process is followed that will introduce the innovation to the masses in the organization and assist in diffusing it through the organization. Consulting and project management may be necessary to assist the organization in implementing this change. Specific project management methodologies are not included as part of this course but are discussed in other courses.

Many change agents stop at the implementation stage, but the last step is very important. This stage is confirmation. In this stage the organization must be encouraged that the decision was the correct one. It is also a good opportunity to find out if the innovation is working as expected or if new problems have developed. If necessary, changes can be made to realize the expected benefits and solve any problems. If this is not done, the organization may decide to abandon using the technology. This results in wasted effort and negative reviews of the product or process. 


\section{Connected by communication}

The third key concept of diffusion theory is that individuals in a system are connected by communication links that enable information to spread. This can be a formal organization structure that communicates "down" to the people in the system or an informal structure like interoffice conversation, lunch groups or other group associations.

The formal structure of the organization is important. It is this structure that controls the resources needed to implement the innovation. It is definitely necessary to have management and other formal leaders accept the innovation in order for it to be successful.

The informal structure is also vital for a smooth implementation. This is often not considered as important as formal leadership, but careful consideration is important since it can reduce costs and problems that can occur during an implementation.

Several years ago while the author was diffusing a new groupware system through a large corporation, the users were showing resistance. The secretaries in the organization were resisting the change because it made some aspects of their jobs harder to perform. They did not understand the benefits of the total system. By examining the causes of this resistance the implementation team was able to understand the concerns of this key user group and make changes that helped the secretaries perform their jobs more effectively. This was accomplished by having implementation team members participate in informal secretarial organizations. The secretaries became allies as a result of this involvement, which greatly improved the implementation process.

\section{Interpersonal influences produce change}

The fourth key concept of diffusion is that interpersonal influences produce change. This is where friends tell friends what they like or dislike about the innovation. The characteristics of the teller become critical here. As mentioned before, the thoughts of the opinion leaders are of utmost importance. If the opinion leader approves or uses the innovation, others will follow.

\section{Gatekeepers}

The fifth key concept is that gatekeepers control access to information. Every organization has gatekeepers. These are people who control access to the information, resources or people needed by the change agent to further the diffusion process. It is not necessarily important that these people adopt the innovation, but they must be supportive if the change agent is to be successful. The gatekeepers can be secretaries, custodians, receptionists or other managers. In the groupware example above, secretaries were preventing whole sub-organizations from moving to the new technology.

\section{Adopter categories}

The sixth key concept is that people adopt innovations at different rates. This is a result of many factors including personality, experience, and socioeconomic level.

If we graph the number of incremental adopters (y-axis) of an innovation in a large system over time (xaxis), the incremental adoption would follow a normal curve as illustrated in Figure 1. The cumulative adopters would form an s-curve.

Rogers (1995) divides this curve into adopter categories based on the innovativeness of the adopter. People adopting early are normally more innovative than those who adopt later. The number of standard deviations from the mean time to adopt is used to classify the individuals. People who adopt most quickly (more than two standard deviations to the left of the mean) are called innovators and form $2.5 \%$ of the population. Innovators are the type of people who are eager for new ideas and love to try new things. They tend to move in circles that expose them to new ideas and are more cosmopolitan in nature. They 


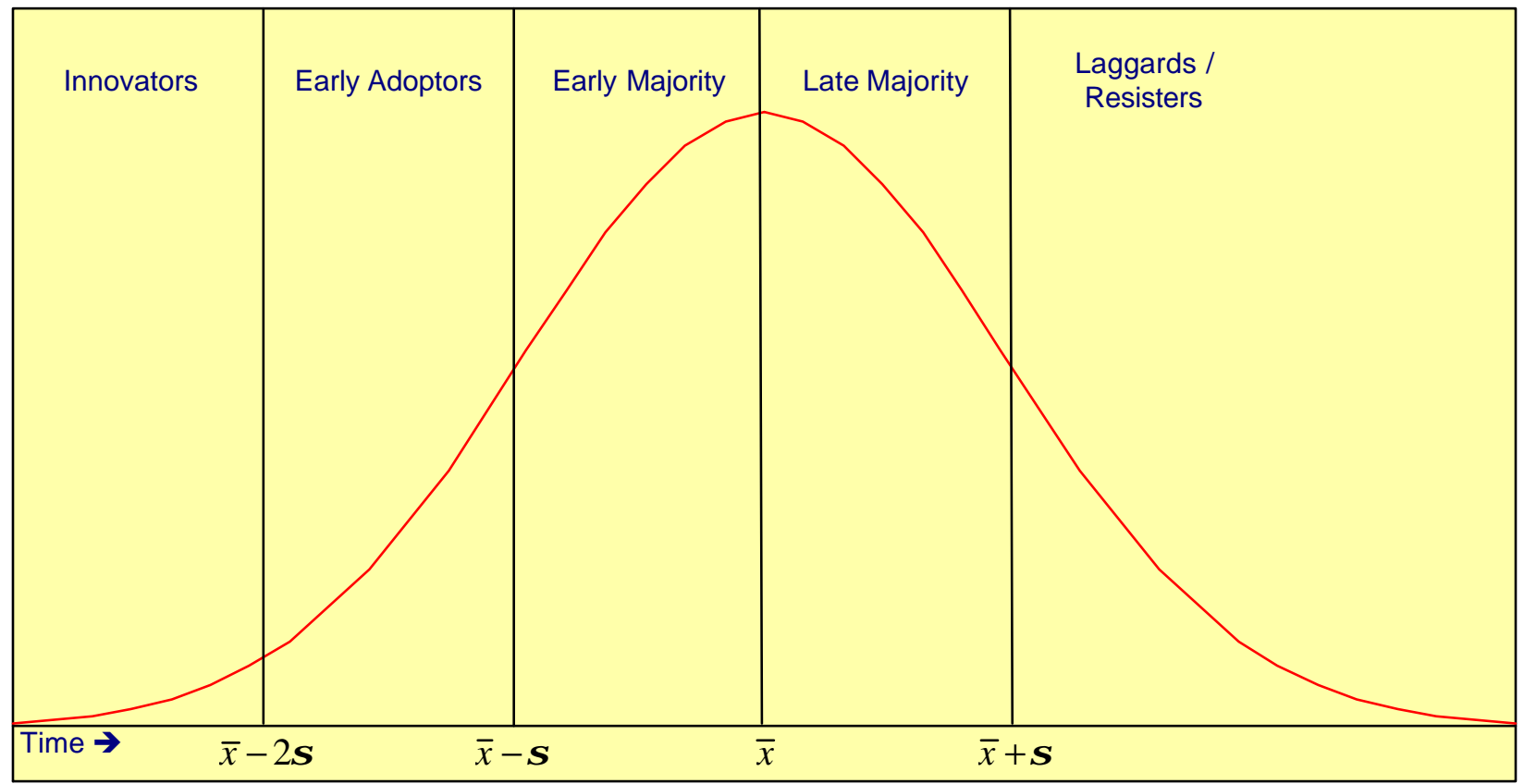

Figure 1 - Adoption curve showing the incremental adoption of an innovation over time (Rogers, 1995)

They have a high tolerance for risk and uncertainty. Often they are not highly respected in the organization, unless the organizational norms favor innovation. People will not usually follow their lead, but they can be very helpful in bringing new technology to the organization and trying out new things.

The second group to adopt is the early adopter category (13.5\% of the population). This group falls between one and two standard deviations to the left of the mean. This group tends to be well connected within the organization. They are a little less tolerant of risk than the innovators, but will quickly adopt an innovation if they see a benefit. They will convey information to their peers and others look to them as role models. It is important for the change agent to understand the members of this group because it produces most of the opinion leaders.

Innovators and early adopters tend to adopt because of the desire for pleasure or increased status (Venkatesh, Viswanath \& Brown, 1998). The majority (68\%) falls between one standard deviation on either side of the mean. The early majority (34\%) will follow with deliberate willingness once they are convinced of the innovation's value, but they will seldom lead. They are strongly influenced by utility and peer pressure (Venkatesh, Viswanath \& Brown, 1998). The late majority (34\%) will remain skeptical. They may have limited resources and will adopt only out of economic necessity or as a result of peer pressure.

The laggards or resisters (16\%) are the last category. They fall to the right of one standard deviation from the mean. Resisters have almost no opinion leadership. They tend to be isolated socially, suspicious of change and support traditional technology and values. They have a low tolerance for risk, which may be a result of their limited resources. They may never be willing to adopt which can present problems for the change agent. The late majority and laggards may fear rapid changes in technology. Many in this category may never adopt unless forced (Venkatesh, Viswanath \& Brown, 1998).

The earlier adopters tend to have more education, a higher social status and more resources at their disposal than the later adopters. Often, people who need the benefits of an innovation the most are the last ones to adopt. This is called the innovativeness-needs paradox (Rogers, 1995). 


\section{Alternative views}

Although this course is primarily based on the work of Rogers (1995), alternative views are also presented. One different view is that of Joseph Henrich (2001). Henrich says that most studies share a common assumption that change happens by environmental learning, that is that individuals select among alternatives by doing a cost/benefit analysis in a rational manner. He argues that this is not primarily the case, but that change results from biased cultural transmission.

The basis of his argument is that environmental learning alone, without biased cultural transmission, will not generate the S-curves referenced above and seen in most of the literature. Environmental learning alone will produce more of an R-curve when showing cumulative adoption, lacking the leading tail of the S-curve. On the other side, biased cultural transmission alone or combined with environmental learning does produce the S-curve referenced in the literature. This culturally biased transmission can take three forms; direct bias transmission results from the cues that arise when the qualities of the innovation interact with norms of the system; prestige-based transmission results when individuals copy the ideas or practices of people they admire; and conformist transmission results when people copy the ideas and behaviors that are expressed by the majority (Henrich, 2001).

He further takes a fresh look at early adopters. The characteristics of innovators and early adopters mentioned above assume that these characteristics cause these individuals to be more likely to adopt earlier than others in the system. Henrich says that this appears this way because the data is biased in that it only includes situations where the innovation did spread. The literature does not explore situations where the innovation did not spread.

His belief is that it is possible that all members are equally likely to adopt early, but subsequent transmission of the innovation depends on the characteristics noted for the early adopters. "When poor, low status individuals innovate nobody copies them, so the trait never diffuses, and they never get into the database as "innovators" (Henrich, 2001).

Despite the interesting differences, the key point we want students to recognize is the need to understand the organization and to find people who will support the diffusion of their innovation. They need to recognize that a good idea is not enough and that the human aspects of diffusion are key considerations.

\section{The perceived characteristics of the innovation}

The seventh and final key concept is that the users' perceptions of the characteristics of the innovation influence its adoption. Often these are the only things considered when trying to diffuse an innovation. It is often thought that a good product will sell itself. Although this is occasionally true, it is usually not the case. The diffusion of an innovation requires a holistic approach that includes organizational issues as well as product issues.

These product characteristics are as follows (Rogers):

- Relative advantage - This characteristic looks at the benefits the organization will receive from the new technology over the existing situation. The advantages may be economic or social (as with fads). The more benefits there are with the innovation, from the user's perspective, the more likely it will be adopted.

- Compatibility - This is the measure of how the innovation fits with what is already in use or in practice in the organization. This includes organizational norms, previously adopted ideas and the needs of the organization. The more compatible an innovation is, the more likely it will be adopted. 
○ Complexity - This is how hard the innovation be to figure out and implement. The intuitiveness of the design and ease with which mistakes can be made will impact adoption. The lower the complexity, the more likely the innovation will be adopted.

○ Trialability - Providing a way for users to try the innovation before they adopt it helps to get the innovation adopted. Some innovations are hard to try, like an Enterprise Resource Planning (ERP) system, but training, site visits and simulations can be used as a substitute.

- Observability - This is how other people will view me when using the innovation. If the users will receive positive recognition for their use of the innovation then they will be more likely to adopt the innovation.

\section{Change Strategies}

Students are presented with change strategies that can be used to diffuse an innovation. These strategies are used at different stages in the change process. A re-educative strategy can be used at any stage, but is most effective in the knowledge or early persuasion stage of the diffusion process. This strategy gives a relatively unbiased presentation of the facts about an innovation and is non-confrontational in nature. It presents a long-term strategy and does not necessarily point to a particular product or process to accept. It also may be used before the innovation is finalized.

Another strategy that is presented is the persuasive strategy. This is most effective in the persuasion stage or decision stage. It is a direct effort to persuade and presents a message that is biased toward the recommended alternative. There may also be emotional appeals. It may produce faster change but results in more antagonism among people in the organization, which may result in long-term difficulty.

The final strategy that is presented is the power strategy. This strategy dictates that an innovation will be implemented and is used when speed of implementation is essential. It requires control over the resources needed to implement and costs money for rewards and punishment. There may be retaliation or a reciprocal power strategy. The power strategy may not be self-sustaining since surveillance may be needed to maintain the change.

\section{Consequences of the Innovation}

Students are presented with the importance of studying consequences. Consequences are the changes that occur to an individual or to a social system as a result of the adoption or rejection of an innovation. Consequences can be positive or negative, intended or unintended. It is important for the change agent to consider the consequences of the innovation, but this is often not done. Change agents often assume that their clients need an innovation and there is a pro-innovation bias. They often assume that all the consequences of the innovation will be positive.

Consideration of the potential consequences of the innovation is important because it will help the change agent and the organization deal with the results of adopting the innovation in the long term. For example, an innovation may require that current employees have different skills than were required in the past. This will help the change agent find ways to upgrade the skills of the employees before it becomes a problem. The author worked on one ERP implementation where customer service employees were going to be entering and using data in the new system. The new system was PC based and used a graphical user interface (GUI). Their old system was character-based. One thing we were able to do early was to train these employees in using a PC, including mouse training. By doing this early, we were able to focus on system training when it was close production.

Similarly, if the innovation will result in requiring fewer people for a task, decisions can be made on retraining and other approaches to dealing with the people who are no longer required. This will result in fewer hard feelings and less anxiety among employees. 


\section{Techniques Used in the Course}

The course is taught using a variety of techniques including lecture, class exercises, current readings, a case study and a simulation exercise of the diffusion process. The simulation exercise involves identifying key people in the organization and simulates a real technical innovation being diffused through a system. It simulates two years in the process and follows adopters though the stages in the innovationdecision process. The goal is to get as many adopters as possible.

During the lecture, instructors share real stories that illustrate the diffusion process. These stories come from industrial, educational and consumer settings. Students comment that the stories are beneficial in illustrating the concepts in the course.

The readings are selected from current periodicals or from the news. As assignments, students are often required to comment on a current event or news story involving technology transfer. The comments are to center around a specific topic in the course. In one example a review of a specific product is given and students must comment on the characteristics of the innovation as perceived by a specific target group.

Several in-class exercises are used. Some of these involve determining radical vs. incremental innovations, product vs. process technology, intended vs. unintended consequences, and positive vs. negative consequences.

The capstone of the course is an analysis of a case study that has been developed by the instructors. It involves all the concepts in the course and relates to both the people and product concerns that students will face in their future endeavors.

\section{The Importance of Teaching Technology Transfer}

"Practitioner and scholarly literature has suggested that technical knowledge is important to the success of software development projects, however, it is not most important. Non-technical factors such as bus iness expertise, management skills, and soft skills, such as effective communication appear to significantly impact the software manager's ability to lead successful projects." Study indicates that high value is placed on human computer interaction (Coleman \& Joy, 2002).

Anecdotal evidence indicates that students find this course to be very useful and relevant after they leave college. Student reviews show that most students have learned the concepts of diffusion theory and the reasons those concepts are important. They indicate that the real stories illustrating the points made in the course convince them of the course's relevance. Some of these comments follow (Holden, Perry, \& Yacci, 2002):

"I enjoyed Tech Transfer more than I expected and learned a great deal more than I expected as well."

"Very good class - - took your section after Needs Assessment last year. I like your class because the anecdotes you tell stick in my head and are interesting."

"His stories about experience in industry were very helpful in understanding the material."

"RIT should teach more courses like this; courses relevant to my future career."

"Very excellent course; good preparation for the corporate culture."

Students also recognize the differences in students with experience compared to those who do not. This is reflected in this quote (Holden, Perry, \& Yacci, 2002):

"Great class, I'd recommend that students take at least 2 co-ops prior to get a feel for the business world prior to TT (Technology Transfer) as it gives them a lot better understanding." 
One interesting observation is that faculty often receives unsolicited feedback from students one or two years after they have graduated. The feedback usually is along the line that "now I finally understand the reason for that Technology Transfer course." One former student stopped a faculty member in the hall one day recently and commented that he did not believe anything he was taught in the Technology Transfer course, but since he had been in industry he found that it was all true. They relate how their experience in the workplace has reinforced the concepts learned in the course.

One manager at a large employer recently related that he was impressed that a one of our graduates asked questions about the organization and who the manager thought were the opinion leaders. When asked, the graduate related that he had learned about this in the Technology Transfer course.

We are convinced that this course is important to the future development of our students, which justifies its position in our core curriculum. One interesting area of future study would be to survey the employers of our graduates to determine if the concepts taught in this course have been applied and have been helpful in diffusing innovations. A similar study of former students the mselves would also be of interest. These two studies would be designed to confirm or deny the anecdotal evidence that supports this course.

\section{Conclusion}

The concepts taught in Technology Transfer are often believed to be "common sense" by many students with little or no work experience, and are often not believed to be relevant to the skill set needed by a technologist.

Although we have not done a scientific survey of the results of teaching the Technology Transfer course to our undergraduate students, we believe there is sufficient anecdotal evidence that the course is beneficial to the students' future career growth. The pattern of this evidence is consistent over the last nine years that this course has been offered at RIT.

The paper describes the work done by Everett Rogers in diffusion research, adopter types, and the characteristics of an innovation. The course embellishes this with practical experience with IT and nonIT innovations. The concepts taught emphasize the need for concern about the population who must adopt the innovation. Although the innovation must be sound, a sound innovation is not sufficient for an innovation to be accepted. Students must learn that the human aspects of diffusing an innovation are as important or possibly more important than the technical innovation itself.

\section{References}

Coleman, Deborah G. \& Joy, Donald A. (2002, September). Software development management abilities, expertise, and styles. Paper presented at the Conference for Information Technology Curriculum, Society for Information Technology Education, Rochester, NY, USA.

Holden, Edward, Perry, Ron, \& Yacci, Michael. (2002, September). Technology transfer-before and after. Paper presented at the Conference for Information Technology Curriculum, Society for Information Technology Education, Rochester, NY, USA.

Henrich, Joseph. (2001, December). Cultural Transmission and the Diffusion of Innovations. American Anthropoligist. retrieved march1, 2003 from http://webuser.bus.umich.edu/henrich/

Rand, Ben. (2002, October 16). Kodak shows off bright baby. Democrat and Chronicle, pp D10, D6.

Rogers, Everett M. (1995). Diffusion of Innovations. (Fourth Edition). New York: The Free Press.

Spence, W.R. (1994). Innovation: the communication of change in ideas, practices, and products. London: Chapman \& Hall.

Venkatesh, Viswanath, \& Brown, Susan A. (1998). A Longitudinal Investigation of Personal Computers in Homes: Adoption Determinants and Emerging Challenges, CSI Working Paper, retrieved November 17, 2002 from www.slis.indiana.edu/csi/WP/wp98-01B.html 


\section{Biography}

Edward Holden is an Assistant Professor in the Information Technology Department of the Golisano College of Computing and Information Sciences at Rochester Institute of Technology (RIT). He teaches courses in programming, database management, technology transfer, needs assessment, e-commerce and process management. Prior to joining RIT full-time, Ed spent 28 years in the Information Systems business at a major corporation. In his last positions he served as the manager of Global Infrastructure Development for Messaging and Groupware and worked on a special assignment to integrate digital bus iness efforts with back office systems and operations. Prior to this he was the manager of Messaging and Groupware for US and Canada where he supervised the outsourcing of email and groupware and the migration of 30,000 users to a new email and groupware system. He also worked on the preliminary design and requirements definition for the company's business-to-business e-commerce initiative. Ed has performed all phases of the systems life cycle from proposal through continued support and the negotiation and management of outsourcing contracts. His clients have included finance, marketing, sales, research and development, and supply chain management.

Ed holds an MBA, Finance, from Rochester Institute of Technology (1995) and a BA in Mathematics from SUNY Oswego (1972). 